respond, the degree of response of blood pressure is less for a given dose in black than white patients. There are no ideal antihypertensive drugs for black patients, and these data suggest that poor compliance does not account for the failure to control blood pressure.

We thank Knoll AG (Burgess Hill) for supplying verapamil and placebo; Astra Ltd (Stoke Poges) for supplying metoprolol and placebo; Dr Peter Frost and colleagues for measuring serum electrolyte and lipid concentrations; Drs Shore and MacGregor (Charing Cross Hospital) for measuring plasma renin activity; Mrs Burnett and Dr Turner (Oxford) for measuring C peptide concentrations; and Nicola Wilson Smith for typing the manuscript. Some of the data were presented at the meeting of the International Society of Hypertension, Heidelberg, 1986. ${ }^{34}$

NMcFA received support from Knoll AG.

1 Cruickshank JK, Jackson S, Beevers G, Bannan L, Beevers M, Stewart V. Similarity of blood pressure in blacks, whites and Asians in England: Similarity of blood pressure in blacks, whites and
Birmingham factory study. F Hypertens 1985;3:365-71.

2 Haines AP, Booroff A, Goldenberg E, Morgan P, Singh M, Wallace P. Blood pressure, smoking, obesity and alcohol consumption in black and white patients in general practice. Foumal of Human Hypertension 1987;1:39-46.

3 Marmot MG, Bulusu L, Adelstein A. Immigrant mortality in England and Wales. London: HMSO, 1984

4 Cruickshank JK, Beevers DG, Osborne V, et al. Heart attack, stroke, diabetes and hypertension in West Indians, Asians and whites in Birmingham, England. Br Med f 1980;281:1108.

5 Pacy P, Dodson P, Beevers M, Fletcher R, Taylor $K$. The ethnic prevalence of hypertension in a diabetic clinic. Postgrad Med f 1983;59:637-40.

6 Cruickshank JK, Alleyne S. Vascular disease in West Indian and white diabetics in Britain compared with Jamaica. Postgrad Med $\mathcal{F} 1981 ; 57: 766-8$.

7 Cruickshank JK, Alleyne S. Black West Indian and matched white diabetics in Britain compared with diabetics in Jamaica: body mass, blood pressure and vascular disease. Diabetes Care 1987;10:170-9.

8 Drury PL. Diabetes and arterial hypertension. Diabetologia 1983;24:1-9.

9 Parving H, Andersen A, Schmidt U, Svendsen P. Early aggressive antihypertensive treatment reduces rate of decline in kidney function in diabetic nephropathy. Lancet 1983;i:1175-9.

10 Hostetter T, Rennke H, Brenner B. The case for intrarenal hypertension in the initiation and progression of diabetic and other glomerulopathies. $\mathrm{Am}$ f Med 1982;72:375-80.

11 Veterans Administration Study Group. Comparison of propranolol and hydrochlor-thiazide for initial treatment of hypertension. I. Results of shortterm titration with emphasis on racial differences in response. IAMA 1982;248:1996-2004

12 Freis ES, Materson B, Flamenbaum W. Comparison of propranolol and hydrochlorthiazide in hypertension: evaluation of renin-angiotensin system. hydrochlorthiazide in hyper

13 Veterans Administration cooperative study. Racial differences in response to low dose captopril are abolished by the addition of hydrochlorthiazide. $B r \mathcal{F}$ Clin Pharmacol 1982;14(suppl 2):97-102.

14 Bühler F, Hulthen UL, Kiowski W, Bolli P. Greater anti-hypertensive efficacy of the calcium channel inhibitor verapamil in older and low renin patients. Clin Sci 1982:63(suppl 8):439-42.

15 Seedat YK. Trial of atenolol and chlorthalidone for hypertension in black South Africans. Br Med $\mathcal{F}$ 1980;281:1241-2.

16 Grell G, Alleyne G, Robinson H, Anderson N. Treatment of Jamaican hypertensives with atenolol and chlorthalidone. West Indian Med f 1981;30: 124-8

17 Moser N, Lunn J. Comparative effects of pindolol and hydrochlorothiazide in black hypertensive patients. Angiology 1981;32:561-6.

18 Grell GAC, Forrester TE, Anderson M, Gibbs P. Oxprenolol and chlorthaldone in the treatment of mild hypertension in Jamaica. Tropical Cardiolog 1987;13:157-63.

19 Cruickshank JK, Beevers DG. Ethnic and geographic differences in blood pressure. In: Bulpitt C, ed. Epidemiology of hypertension. Cambridge: Elsevier, 1985:70-87.

20 Cresanta JC, Burke GL. Determinants of blood pressure levels in children and adolescents. In: Berenson GS, ed. Causation of cardiovascular risk factors in children. New York: Raven Press, 1986:171-2.

21 Berenson GS, Voors AW, Webber LS, Dalferes ER, Haksha DW. Racial differences in parameters associated with blood pressure levels in childrenthe Bogars part

22 Luft FC, Grimm CE, Fineberg N, Weinberger ME. Effects of volum expansion and contraction in normotensive whites, blacks and subjects of different ages. Circulation 1979;59:643-51.

23 Cubeddu LX, Aranda J, Singh B, et al. Comparison of verapamil and propranolol for the initial treatment of hypertension. JAMA 1986;256: 2214-21

24 Massie B, McCarthy P, Ramanathan K, et al. Diltiazam and propranolol in mild to moderate essential hypertension. Ann Intern Med 1987;107:150-7.

25 Andersson DE, Rojdmark S. Improvement of glucose tolerance by verapam in patients with non-insulin dependent diabetes mellitus. Acta Med Scand 1981;210:27-33.

26 Miller GJ. Lipids and coagulation factors. In: Cruickshank JK, Beevers DG eds. Ethnic factors in health and disease. London: Butterworth (in press).

27 Miller GJ, Miller NE, Ashcroft MT. Inverse relationship in Jamaica between plasma HDL-cholesterol and coronary disease risk as predicted by multiple plasma HDL-cholesterol and coronary disease risk
risk factor status. Clin Sci Mol Med 1976;51:475-82.

28 Beckles GLA, Miller GJ, Kirkwood BR, et al. High total and cardiovascular disease mortality in adults of Indian descent in Trinidad, unexplained by major coronary risk factors. Lancet 1986; i: 1298-1301.

29 Taguma Y, Katamoto Y, Futaki G, Ueda $\mathrm{H}$, et al. Effect of captopril on heavy proteinuria in azotemic diabetics. $N$ Engl $\mathcal{G}$ Med 1985;313:1617-20.

30 Hómmel E, Parving HH, Mathiesen E, et al. Effect of captopril on kidney function in insulin-dependent diabetic patients with nephropathy. $\mathrm{Br} \mathrm{Med}$ $1986 ; 293: 467-70$

31 Bjorck S, Byberg G, Mulec $\mathrm{H}$, et al. Beneficial effects of angiotensin converting enzyme inhibition on renal function in patients with diabetic nephropathy. BrMed f 1986;293:471-4.

32 Cruickshank JK, Anderson NMcF, Haines AP. 'Spot' urinary albumin/ creatinine: a positive independent relation to systolic blood pressure in the general population, an index of vascular risk? Clin Sci 1987;72(suppl 16):43. [Abstract.]

33 Cruickshank JK, Dickens C, Greenwood RM, Mahler RF, Rinsler M. Repeatability, sensitivity and specificity of spot urine albumin/creatinine Repeatability, sensitivity and specificity of spot urine albumin/creatinine
ratios against overnight excretion rates. Diabetic Med 1987;4:385. ratios agains

34 Cruickshank JK, Anderson NMcF. A trial of verapamil compared with metoprolol in black and white hypertensive diabetics. $\mathcal{f}$ Cardiovas Pharmacol 1987;10(suppl 10):85. [Abstract.]

(Accepted 26 fuly 1988 ,
Department of Surgery,

Charing Cross and

Westminster Medical

School, London W6 8RP

Stephen D Blair, FRCS, senior surgical registrar

David D I Wright, FRCS,

lecturer in surgery

Christopher M Backhouse,

FRCS, surgical registrar

Elizabeth Riddle, SRN,

research assistant

Charles N McCollum, FRCs,

reader in surgery

Correspondence to: $\mathrm{Mr}$ McCollum.

\title{
Sustained compression and healing of chronic venous ulcers
}

\author{
Stephen D Blair, David D I Wright, Christopher M Backhouse, Elizabeth Riddle, \\ Charles N McCollum
}

Abstract

Study objective-Comparison of four layer bandage system with traditional adhesive plaster bandaging in terms of $(a)$ compression achieved and (b) healing of venous ulcers.

Design-Part of larger randomised trial of five different dressings.

Setting-Outpatient venous ulcer clinic in university hospital.

Patients - (a) Pressure exerted by both bandage systems was measured in the same 20 patients. (b) Healing with the four layer bandage was assessed in 148 legs in 126 consecutive patients (mean age 71 (SE 2); range 30-96) with chronic venous ulcers that had resisted treatment with traditional bandaging for a mean of $27 \cdot 2$ (SE 8) months.

Interventions - (a) Four layer bandage system or traditional adhesive plaster bandaging for pressure studies; (b) four layer bandaging applied weekly for studies of healing.

End points-(a) Comparison of pressures achieved at the ankle for up to one week; (b) complete healing within 12 weeks.

Measurements and main results-(a) Four layer bandage produced higher initial pressures at the ankle of 42.5 (SE 1) mm Hg compared with 29.8 (1.8) for the adhesive plaster $(p<0.001 ; 95 \%$ confidence interval 18.5 to 6.9). Pressure was maintained for one week with the four layer bandage but fell to 10.4 (3.5) $\mathrm{mm} \mathrm{Hg}$ at 24 hours with adhesive plaster bandaging. (b) After weekly bandaging with the four layer bandage 110 of 48 venous ulcers had healed completely within 12 (mean $6.3(0.4)$ ) weeks.

Conclusion-Sustained compression of over $40 \mathrm{~mm} \mathrm{Hg}$ achieved with a multilayer bandage results in rapid healing of chronic venous ulcers that have failed to heal in many months of compression at lower pressures with more conventional bandages.

\section{Introduction}

Venous or gravitational ulcers result from failure of the calf muscle pump due to venous incompetence, 
paralysis, or immobility. The resulting venous and capillary hypertension increases permeability and produces tissue oedema and perivascular deposition of fibrin, which creates a barrier to diffusion around the capillaries and results in necrosis. ${ }^{1}$ The need for compression to reverse the effects of venous and capillary hypertension has been recognised for centuries, ${ }^{2}$ but adequate studies on the amount of compression required for optimal healing and how this might be sustained in patients with large and discharging venous ulcers have not been performed. Without compression, healing rates of $30 \%$ at 10 weeks have been reported as acceptable ${ }^{34}$; when compression with standard gauze and elastic bandages was applied healing rates were about $45 \%$ at 12 weeks. $^{56}$

An external pressure of $35-40 \mathrm{~mm} \mathrm{Hg}$ at the ankle has been calculated to be necessary to prevent capillary transudation in legs severely affected by venous disease. ${ }^{7}$ We designed a system of bandages to achieve and sustain this compression for at least one week and tested this bandage in our venous ulcer clinic, where for many years bandages of gauze impregnated with zinc held in place by adhesive plaster had been used to treat venous ulcers. Five different dressings were used; only one, pinched skin grafts, significantly influenced healing. ${ }^{89}$

\section{Patients and methods}

In our clinic 126 patients (148 legs) had chronic venous ulcers that had resisted treatment of bandaging with gauze impregnated with zinc and adhesive plaster for a mean of $27 \cdot 2$ (SE 8) months. On their entry to this study full clinical evaluation was repeated and included Doppler assessment of arterial pressure at the ankle. Patients with arterial disease and an ankle:brachial arterial pressure ratio of less than 0.8 had been excluded as they were at risk of necrosis from high compression bandaging.

The original bandage system was one widely used throughout the country-namely, an initial layer of gauze impregnated with zinc compressed by Elastocrepe and kept firmly in place by adhesive plaster. The new four layer bandage incorporated an inner layer of orthopaedic wool (Velband; Johnson and Johnson) to absorb any exudate and redistribute pressure around the bony high points of the ankle. This was compressed with a standard crêpe bandage (Elset; Seton), which preserved the elastic energy of the main compression bandage and made application easier. Finally, a lightweight elasticated cohesive bandage (Coban; 3M United Kingdom) maintained the bandage in place for a full week. All bandages were applied at mid-stretch so that compression was achieved more by elasticity and overlap than by the tension applied by the bandager.

The patients' ulcerated legs were randomly assigned to be dressed with one of five dressings: 43 received a non-adhesive dressing (NA; Johnson and Johnson), 25 received pinch skin grafts, 26 received a hydrocolloidal dressing (Granuflex; Squibb Surgicare), 28 received porcine dermis (Johnson and Johnson), and 26 received silver sulphadiazine (Flamazine; Smith and Nephew Pharmaceuticals).

Pressure measurements with both types of bandage

TABLE I-Mean (SE) pressures ( $\mathrm{mm} \mathrm{Hg}$ ) exerted by adhesive plaster and four layer bandages immediately after bandaging

\begin{tabular}{lcccc}
\hline & $\begin{array}{c}\text { Adhesive plaster } \\
(\mathbf{n}=20)\end{array}$ & $\begin{array}{c}\text { Four layer bandage } \\
(\mathbf{n}=20)\end{array}$ & $\begin{array}{c}\text { Difference } \\
(\text { significance })\end{array}$ & $\begin{array}{c}95 \% \\
\text { Confidence interval }\end{array}$ \\
\hline Medial malleolus & $29 \cdot 8(1 \cdot 8)$ & $42 \cdot 5(1 \cdot 0)$ & $-12 \cdot 7(\mathrm{p}<0 \cdot 001)$ & $18 \cdot 5$ to 6.9 \\
Gaiter & $19 \cdot 4(1 \cdot 9)$ & $38 \cdot 8(1 \cdot 5)$ & $-19 \cdot 4(\mathrm{p}<0 \cdot 001)$ & $25 \cdot 2$ to $13 \cdot 6$ \\
Calf & $12 \cdot 9(2 \cdot 1)$ & $35 \cdot 1(1 \cdot 3)$ & $-22 \cdot 2(\mathrm{p}<0 \cdot 001)$ & $27 \cdot 2$ to $17 \cdot 1$ \\
Below knee & $5 \cdot 8(0 \cdot 5)$ & $17 \cdot 2(1 \cdot 7)$ & $-11 \cdot 4(\mathrm{p}<0 \cdot 001)$ & $17 \cdot 7$ to $5 \cdot 0$
\end{tabular}

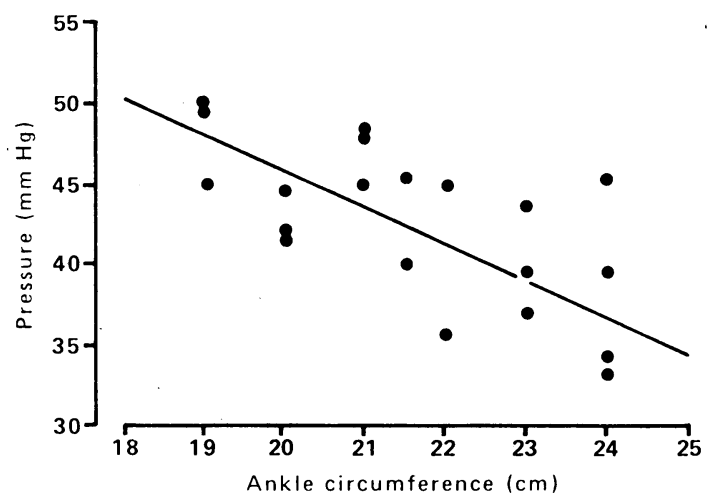

FIG 1 -Relation of compression by four layer bandage and circumference of ankle $(r=-0.63 ; p<0.01)$

sequentially were made on 20 consecutive patients. Compression was measured $2 \mathrm{~cm}$ above the medial malleolus, in the gaiter area, at mid-calf, and below the knee with a medical stocking tester (Saltzman, Switzerland). The adhesive plaster bandage was applied by the existing clinic staff, who were experienced in its use and satisfied with the results; the four layer bandage was applied by those who introduced it. Thus the comparison was betweeen adhesive plaster bandaging as applied by its proponents and the four layer bandage as applied by its supporters. Four, eight, and 24 hours and seven days after bandaging the pressures were measured $5 \mathrm{~cm}$ above the medial malleolus with an Oxford pressure monitor (Tally Medical UK), which was both less cumbersome and more accurate over prolonged periods than the medical stocking tester. The length of the legs and their circumference at both the ankle and calf were measured and correlated with compression. The variation in measurements of pressure achieved by different members of the team was also analysed.

Each week the ulcers were cleaned with saline before being rebandaged in the outpatient department. The total area of ulceration on each leg was measured each week: the margins were traced on to acetate sheets, the tracings were transferred on to card with a known ratio of area to weight, and the card was cut out, weighed, and converted to the total area of ulceration on each leg. When ulcers had healed the patients were fitted with high compression elastic stockings (Sigvaris; Camp) and reviewed at intervals of three months for signs of recurrence. Ulcers that had not healed at 12 weeks were considered to be treatment failures; and these patients then underwent full assessment with a view to operation.

Differences in compression and rates of healing between the two bandages were assessed by the non-parametric Mann-Whitney U test.

\section{Results}

Bandages of gauze impregnated with zinc, Elastocrepe, and adhesive plaster produced a mean pressure at the medial malleolus of $29.8(\mathrm{SE} 1.8) \mathrm{mm} \mathrm{Hg}$; the pressure fell gradually to only $5.8(0.5) \mathrm{mm} \mathrm{Hg}$ below the knee (table I). The four layer bandage achieved significantly higher pressures: mean pressures were $42.5(1) \mathrm{mm} \mathrm{Hg}$ at the medial malleolus and $17 \cdot 2(1 \cdot 7)$ $\mathrm{mm} \mathrm{Hg}$ just below the knee $(\mathrm{p}<0.001)$. Furthermore, the pressures achieved by different bandagers were more consistent with the four layer bandage: initial pressures at the ankle ranged from 33 to $50 \mathrm{~mm} \mathrm{Hg}$ compared with 18 to $55 \mathrm{~mm} \mathrm{Hg}$ with adhesive plaster. Figure 1 shows the inverse relation between the circumference of the ankle and pressure at the ankle $(r=-0.63, p<0.001)$; the shape of the leg was the main reason for graduated compression.

Measurements with the pressure monitor showed 
that compression under the standard adhesive plaster bandage deteriorated rapidly. Ankle pressure fell to 15.5 (SE 3.2) $\mathrm{mm} \mathrm{Hg}$ at four hours and 10.4 $(3.7) \mathrm{mm} \mathrm{Hg}$ at 24 hours $(\mathrm{p}<0.001)$ (fig 2$)$. In contrast, the pressure under the four layer bandage rose from $40.0(2 \cdot 8) \mathrm{mm} \mathrm{Hg}$ to $44.5(2 \cdot 1) \mathrm{mm} \mathrm{Hg}$ at eight hours. By the next morning the mean pressure had returned to near initial values and one week later was only $3.7 \mathrm{~mm} \mathrm{Hg}$ lower, at $36.3(3.7) \mathrm{mm} \mathrm{Hg}$ (fig 2).

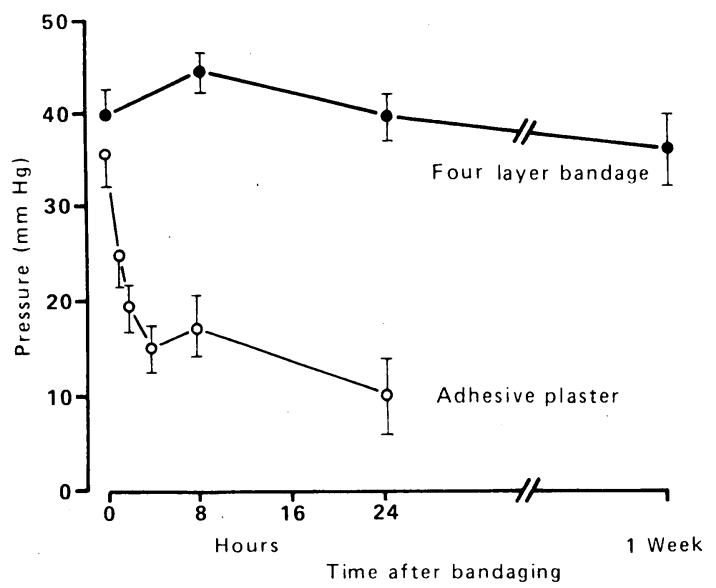

FIG 2-Mean (SE) pressure exerted just above medial malleolus by adhesive plaster and four layer bandage

The 148 ulcerated legs had been treated with adhesive plaster bandaging for a mean of $27 \cdot 2(8 \cdot 0)$ months. The mean age of the patients was 71 (2) (range $30-96$ ), and 22 patients gave a clear history of a deep venous thrombosis. The mean area of ulceration was $15.4(6.8) \mathrm{cm}^{2}$ when the four layer bandage was first applied, after which healing was rapid. A peak healing rate of $3.5(1.2) \mathrm{cm}^{2} /$ week was achieved during the second week. During the 12 weeks of study 110 of the 148 ulcers healed completely in a mean time of 6.3 $(0.4)$ weeks (table II).

Compliance in wearing the Sigvaris high pressure stockings was good, and 111 patients wore them regularly at one year. The rate of recurrence of ulcers in this group was $22 \%$ (24) compared with $45 \%$ (7) in the few patients who failed to comply.

\section{Discussion}

Compression by adhesive plaster bandaging seems to be inadequate $(30 \mathrm{~mm} \mathrm{Hg}$ ), to depend on the technique of application, and to dissipate rapidly after a few hours. In contrast, the four layer bandage achieved pressures of about $40 \mathrm{~mm} \mathrm{Hg}$, which depended less on the bandager and were sustained for at least one week. The slight rise in pressure at eight hours may be attributable to swelling of the foot during the day and presumably occurred each day.

Compression was related to the diameter of the ankle and was greater in patients with small ankles. This can be predicted from Laplace's law; the pressure in a cylinder exerted by uniform tension in the wall is inversely proportional to the radius. Graduated compression was therefore applied automatically when the same tension and overlap were used, as the radius of the leg increases from ankle to calf. The consistent compression with the four layer bandage is due to the overlap and elasticity of the bandages, which achieve the pressure when bandages are applied at mid-stretch. Different people using one bandage may apply widely different pressures as single bandage systems rely on the skill of the bandager. ${ }^{10}$ Furthermore, in a multilayer system the mistakes in tension in any one layer will tend to be averaged out. The danger of applying too high a pressure, particularly in the absence of arterial pulses, has been reported recently. ${ }^{14}$ Other studies reported that up to one quarter of the initial pressure under adhesive plaster bandages dissipated within 30 minutes, and three quarters of the pressure under a single elastic bandage dissipated within eight hours. ${ }^{112}$ The four layer bandage seems to be unique in producing the necessary compression to prevent capillary transudation and in sustaining it over a full week.

The rate of complete healing achieved by 12 weeks in our study ( $74 \%$ of the ulcers) may be compared with recent reports of $30 \%$ healed without any compression and $45 \%$ healed with elasticated bandages in similar periods. ${ }^{3-6}$ This wide range of rates of healing emphasises the need to determine the optimal compression required. It almost certainly varies among patients and needs to take into account height, weight, and severity of venous insufficiency.

The benefits of adequate compression may be realised in the large population of patients with ulcers only when truly elastic bandages similar to those used in this study are available in the community. These bandages should be made available to district nurses and general practitioners (they are currently not prescribable on form FP10), or some alternative combination of materials already available on prescription should be evaluated by similar methods. Although a multilayer bandage may seem expensive, the hospita contract price for 12 weeks' bandaging to heal an ulcer is $£ 49$, which is negligible when compared with the cost of employing a district nurse to dress ulcers that fail to heal ( $\$ 5200$ a year).

We are grateful to Johnson and Johnson, Camp UK, and $3 \mathrm{M}$ Health Care for their financial support, which funded the venous ulcer clinic and its associated research.

1 Browse NL, Burnand KG. The causes of venous ulceration. Lancet 1982;ii: 243-5.

. Venous ulceration. Br Med f 1983;286:1920-2.

3 Stewart AJ, Leaper DJ. Treatment of chronic leg ulcers in the community: a comparative trial of Scherisorb Iodosorb. Phlebology 1987;2:115-21.

4 Ormiston MC, Seymour MTJ, Venn GE, Cohen RI, Fox JA. Controlled trial of Iodosorb in chronic venous ulcers. Br Med f 1985;291:308-10.

5 Ryan TJ, Given HF, Murphy JJ, Hope-Ross M, Bynes G. The use of a new occlusive dressing in the management of venous stasis ulceration. In: Ryan TJ, ed. An environment for healing: the role of occlusion. London: Royal Society of Medicine, 1984:99-103.

6 Eriksson G. Comparative study of hydrocolloid dressing and double layer bandage in treatment of venous stasis ulceration. In: Ryan TJ, ed. An environment for healing: the role of occlusion. London: Royal Society of Medicine, 1984:111-3.

7 Stemmer R. Ambulatory elasto-compressive treatment of the lower extremities particularly with elastic stockings. Der Kassemarzt 1969;9:1-8.

8 Backhouse CM, Blair SD, Savage AP, Walton J, McCollum CN. Controlled trial of occlusive dressings in healing chronic venous ulcers. $\mathrm{Br} \mathcal{F}$ Surg 1987;74:626-7.

9 Poskitt KR, Lloyd-Davies ERV, James A, Walton J, McCollum CN. Pinch grafting or porcine dermis in venous ulcers: a randomised clinical trial. $\mathrm{Br}$ Med F 1987;294:674-6.

10 Fentern PH, Goddard M, Gooden BA, Yeung CK. Control of distension of varicose veins achieved by leg bandages as used after injection sclerotherapy. BrMed f 1976;ii:725-7.

1 Dale J, Callam M, Ruckley CV. How efficient is a compression bandage? Nursing Times 1983 Nov 16:49-51.

12 Ray TB, Goddard M, Makin GS. How long do compression bandages maintain their pressure during ambulatory treatment of varicose veins. $\mathrm{Br} \mathcal{F}$ Surg 1980;67:122-4.

13 Pottle B. Trial of a dressing for non-healing ulcers. Nursing Times 1987 March 25:54-8.

14 Callam MJ, Ruckley CV, Dale JJ, Harper DR. Hazards of compression treatment to the leg: an estimate from Scottish surgeons. Br Med $\mathrm{J}$ 1987;295:1382.

(Accepted 5 August 1988) 